\title{
Study of the Cooling Process of an Extruded Aluminium Profile
}

\author{
C. Bouffioux*, M. Carton ${ }^{+}$, J. Lecomte-Beckers ${ }^{+}$, A.M. Habraken* \\ ${ }^{*} M \& S$ department- sector: Mechanic of Solids and Material, ${ }^{+}$ASMA department- sector: Metallic Materials \\ University of Liège
}

\begin{abstract}
The prediction of the final axial stresses and the residual strains of complex extruded aluminium profiles requires a good knowledge of the material behavior and of the industrial process. This paper is focused on the methods required to provide the whole set of data: material ones and process ones. Scanning differential calorimetry, dilatometry and diffusivity tests identify thermophysic material properties and hot tensile tests identify parameters of the elastovisco-plastic Norton-Hoff law. The description of the industrial process and its simulations are described. Then a sensitivity analyzis provides the cooling key parameters causing the undesired final curvature during the industrial process.
\end{abstract}

\section{INTRODUCTION}

The extrusion of metal allows to produce complex shape by pressing a hot billet through a die. With their good ductility at low temperature, the aluminium alloys are appropriate for this process.

The material is heated before pressing, this temperature must be high enough to ensure the dissolution of $\mathrm{Mg}_{2} \mathrm{Si}$ precipitates but not too high to avoid melting of the matter during the extrusion. Rate and temperature of dissolution are chosen to avoid grain growth and recrystallisation during extrusion. When passing through the die, the temperature in the aluminium alloy increase locally because of friction and dissipation of plastic work. Then, a quench ensures to preserve as nearly as possible the solid solution. High quenching rates are necessary to obtain good final hardness during subsequent natural ageing.

Quenching is in many way the most critical step in the sequence of heat treating operations. This cooling step induces heterogeneities in the temperature field in the profile section and causes residual stresses and strains. This point is studied in this paper.

Rails of cars seats produced by extrusion with 6082 aluminium alloy have been analyzed in order to define the factors affecting the straightness of the produced profiles.

\section{INDUSTRIAL PROCESS}

Cylindrical billets are heated by induction at the temperature of approximately $500^{\circ} \mathrm{C}$. The hot billet is then inserted in the extrusion chamber. A press force is applied. The metal is then extruded through a die with the shape of the required section.

The profiles are then cooled down by a device of water and air sprays in order to quickly achieve the temperature below $250^{\circ} \mathrm{C}$. Water reaches all surfaces of the section. The cooling speed is important to ensure a good final hardness. During this step, the profiles are maintained by guides.

After the exit of the cooling tunnel, the profiles are not any more blocked and this freedom of displacements results in profile distortion for some profile shapes. A final curvature happens. The objective of this study is to understand better the responsible factors of this observation.

The profiles are then stretched and straightened. 


\section{RESEARCH DESCRIPTION}

The first step of this study is to obtain material parameters by differential thermal analyses, dilatometry, diffusivity and by hot tensile tests. The results of these tests are exploited to provide material characteristics at various temperatures.

The second step studies quench process and adjusts heat transfer parameters by comparison between industrial cooling speed and results of thermal FEM analyses.

With all these data, a reference F.E.M. thermomechanical simulation, representative of the actual process, is defined.

Then a sensitivity study is performed to define the impact of different parameters on final strains and curvature.

\section{PRECIPITATES DESCRIPTION}

Laboratory of metallic materials (ASMA) has extracted samples out of a billet to observe the microstructure, to distinguish the various precipitates and to verify the effectiveness of the setting in solution of the precipitates.

It was observed that the heating operation at $500^{\circ} \mathrm{C}$ is not sufficient to dissolve the silicon precipitates.

\section{MATERIAL CHARACTERISATION}

Because of impossibility to take material samples between extrusion exit and cooling process, we obtained pieces of material extracted after quench and before straightening. Then, there can be a difference between characterized material and actual material before cooling.

\section{Thermophysic properties}

Laboratory of metallic materials (ASMA) has measured the thermophysic properties described below by differential thermal analyses, dilatometry and diffusivity tests. Their results agree with thermophysic properties found in [1] for this type of aluminium alloy.

\section{Thermal expansion coefficient: $\alpha$}

A sample of 6082 (length $=25 \mathrm{~mm}$ ) was introduced into a dilatometer and was subjected to a temperature gradient. The length variations are measured and make possible to calculate the dilation of material. Tests were carried out by heating and cooling conditions, for several speeds. These length variations were similar for all the cases.

\section{Density: $\rho$}

Density is calculated by taking the variation of mass and length into account while the sample is subjected to a variation de temperature. The mass variation is measured by thermogravimetry. It was observed that density variation is almost linear with the heating and with cooling.

$$
\text { Specific heat mass: } C_{p}
$$

These data are obtained by Differential Scanning Calorimetry (DSC). So, specific heat mass is calculated from DSC with the measure of the difference of energy between a reference material and the material to be tested while heating and cooling.

\section{Thermal conductivity: $\lambda$}

Thermal conductivity is calculated from specific heat mass $C_{p}$, density $\rho$ and thermal diffusivity. Diffusivity is measured by laser flash.

TABLE 1.6082 - Thermophysic properties

\begin{tabular}{ccccc}
\hline Temp $\left({ }^{\circ} \mathbf{C}\right)$ & $\begin{array}{c}\text { Coef. of thermal } \\
\text { expansion: } \boldsymbol{\alpha} \\
\left(\mathbf{K}^{-\mathbf{1}}\right)\end{array}$ & $\begin{array}{c}\text { Density: } \boldsymbol{\rho} \\
\left(\mathbf{g} / \mathbf{c m}^{\mathbf{3}}\right)\end{array}$ & $\begin{array}{c}\text { Specific heat mass: } \mathbf{C}_{\mathbf{p}} \\
(\mathbf{J} / \mathbf{g} . \mathbf{K})\end{array}$ & $\begin{array}{c}\text { Thermal } \\
\text { conductivity: } \boldsymbol{\lambda} \\
\mathbf{W} / \mathbf{m} . \mathbf{K})\end{array}$ \\
\hline 100 & $19.6 .10^{-6}$ & 2.69 & 0.930 & 174.5 \\
300 & $25.7 .10^{-6}$ & 2.64 & 0.936 & 181.7 \\
500 & $27.6 .10^{-6}$ & 2.60 & 1.196 & 203.9 \\
\hline
\end{tabular}




\section{Mechanical properties}

\section{Young modulus and Poisson ratio}

The data used for the simulations are referred to 6061 alloy (with similar composition) [2].

TABLE 2. 6061 - T6 - Elastic properties

\begin{tabular}{ccc}
\hline Temp $\left({ }^{\circ} \mathbf{C}\right)$ & $\begin{array}{c}\text { Young modulus: } \\
\mathbf{E} \\
\left(\mathbf{N} / \mathbf{m m}^{\mathbf{2}}\right)\end{array}$ & Poisson ratio: $\mathbf{v}$ \\
\hline 100 & 74900 & 0.35 \\
300 & 67600 & 0.33 \\
500 & 52300 & 0.35 \\
\hline
\end{tabular}

Parameters for the thermal elasto-visco-plastic law

Different hot tensile tests at constant temperature $\left(50,300\right.$ and $\left.500^{\circ} \mathrm{C}\right)$ and at constant strain rate $\left(0.0001,0.0005\right.$ and $\left.0.001 \mathrm{sec}^{-1}\right)$ were performed by M\&S laboratory. The stress-strain curves highlight the influence of the temperature and the strain rate on the stress level.

At low temperature $\left(50^{\circ} \mathrm{C}\right)$, the impact of strain rate is not visible.

The tests could not be carried out quickly after the extraction of the samples. Then, it is possible that the material underwent an ageing.

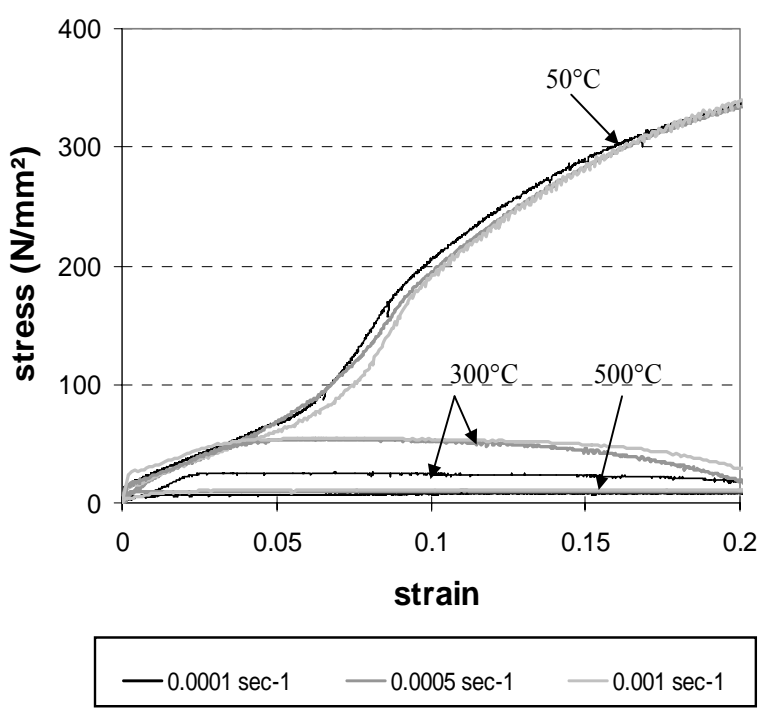

FIGURE 1. Experimental stress-strain curves.
The elastoviscoplastic Norton-Hoff law was chosen for his sensibility to temperature and to strain rate. The experimental data allow to identify the law parameters:

$$
\bar{\sigma}=K_{0} \cdot \bar{\varepsilon}^{p_{4}} \cdot \exp \left(-p_{1} \cdot \bar{\varepsilon}\right) \cdot p_{2} \cdot \sqrt{3} \cdot(\sqrt{3} \cdot \overline{\dot{\varepsilon}})^{p_{3}}
$$

$$
\begin{aligned}
& p_{1}=\left(\frac{T}{c_{1}}\right)^{c_{2}}+c_{3} \\
& p_{2}=\left(\frac{c_{4}}{T}\right)^{2}-\frac{c_{5}}{T}+c_{6}
\end{aligned}
$$

As limited strains appear during cooling, the law is identified for small strains only ( $\varepsilon \leq 0.05$ ).

TABLE 3. 6082 parameters for small strains

\begin{tabular}{ccccccc}
\hline $\begin{array}{c}\text { Temp } \\
\left({ }^{\circ} \mathbf{C}\right)\end{array}$ & $\begin{array}{c}\text { Temp. } \\
(\mathbf{K})\end{array}$ & $\mathbf{K}_{\mathbf{0}}$ & $\mathbf{P}_{\mathbf{1}}$ & $\mathbf{P}_{\mathbf{2}}$ & $\mathbf{P}_{\mathbf{3}}$ & $\mathbf{P}_{\mathbf{4}}$ \\
\hline 50 & 323.15 & 150. & 0.001 & 1.949 & 0.02 & 0.649 \\
300 & 573.15 & 150. & 7.478 & 12.19 & 0.310 & 0.558 \\
500 & 773.15 & 150. & 1.045 & 0.185 & 0.152 & 0.156 \\
\hline
\end{tabular}

With these parameters, we obtain the following curves:

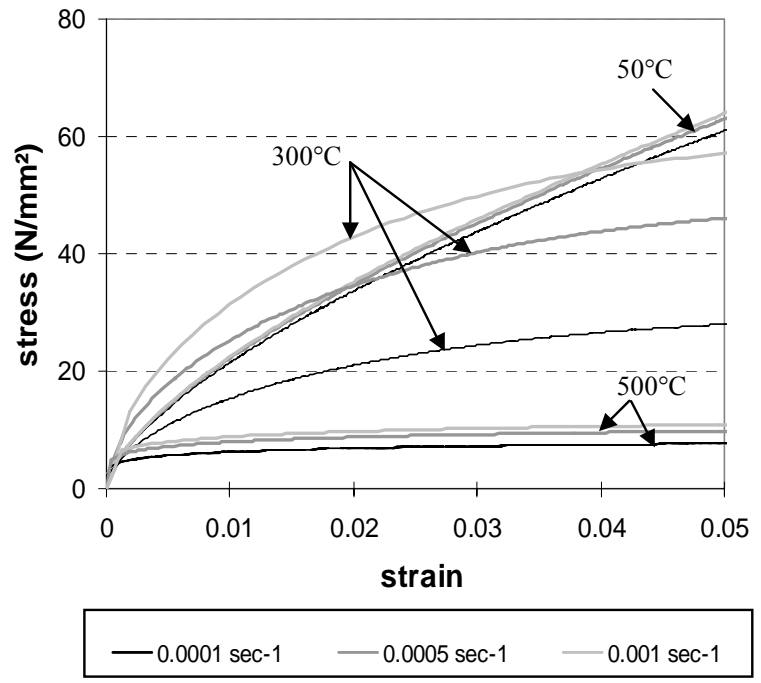

FIGURE 2. 6082 stress-strain curves (only for $\varepsilon \leq 0.05$ ).

\section{INDUSTRIAL MEASUREMENTS}

Infrared temperature measurements performed in the industry have provided some information about the surface temperature between the end of the extrusion process and the water spray. This operation is not easy because of the small size of profiles, the inaccessibility 
of some faces, the speed of pieces,... We measured a temperature near $500^{\circ} \mathrm{C}$ and a variation in temperature from approximately 30 to $50^{\circ} \mathrm{C}$. The thickest zones are the hottest. For the reference study, a homogeneous temperature $\left(500^{\circ} \mathrm{C}\right)$ is considered. The influence of the temperature gradient will be analyzed later (sensitivity analyze).

After cooling, temperature is uniform (about $20^{\circ} \mathrm{C}$ ).

\section{SEEK MISSING PARAMETERS}

For air cooling, natural convection happens, the heat transfer process is well known and the magnitude of the heat convection coefficient is easy to find in literature. For immersion in water or water spray cooling, the evaluation of heat transfer coefficients is not trivial. The process is more complex, steam bubbles temporarily reduce the heat transfer. So the speed of the cooling process depends on numerous factors:

- the profile geometry, the nature of material and its surface quality,

- the effectiveness of water sprays, the geometry of the environment and the water temperature.

So, important differences among authors are observed [3], [8].

It was impossible to place a thermocouple in the section. Finally, we chose to adjust two global transfer coefficients: one for the external surface: $h_{e}$ and one for the internal surface: $h_{i}$ of the section. Different cases were tested: $h_{i}=h_{e}$ and $h_{i}<h_{e}$ for several values of $h_{i}$ and $h_{e}$, homogeneous initial temperature field or gradient temperature field.

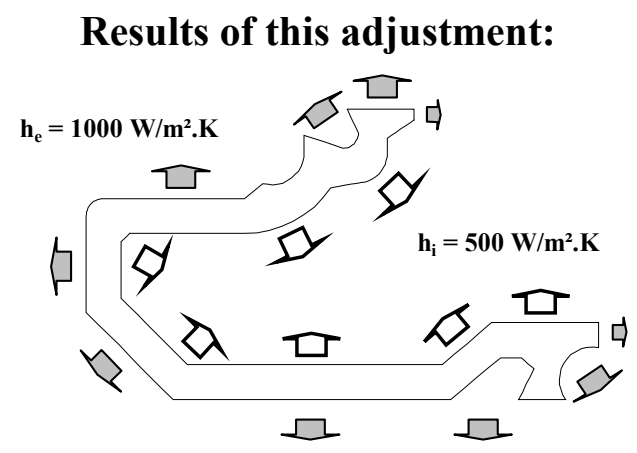

FIGURE 3. Heat transfer coefficients
The coefficients $h_{e}=1000 \mathrm{~W} / \mathrm{m}^{2} . K$ and $h_{i}=500$ $\mathrm{W} / \mathrm{m}^{2} . \mathrm{K}$ were chosen to reach the industrial cooling rate starting with a profile at initial homogeneous temperature at $500^{\circ} \mathrm{C}$.

The final temperature field obtained with these coefficients is coherent with industrial observations (Figure 4).

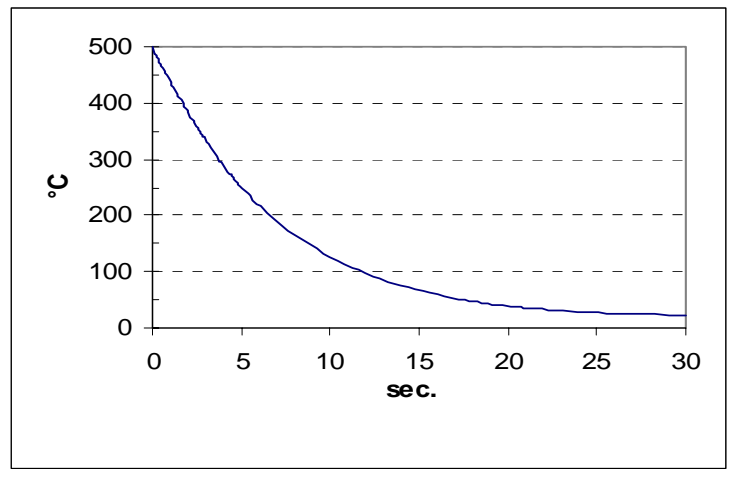

FIGURE 4. Evolution of surface temperature during cooling

\section{CHOISE OF A REFERENCE CASE}

The non linear finite element code LAGAMINE [5], [6] developed by M\&S department has been used for all FEM simulations. A first reference thermomechanical simulation (case 1), representative of the process has been studied by generalized plane state simulation [7]. The evolution of a section of profile is examined. At each moment, the thickness $\mathrm{T}$ is given by the equation:

$$
T=\alpha_{0}+\alpha_{1} X+\alpha_{2} Y
$$

So, the evolution of $\alpha_{0}, \alpha_{1}$ and $\alpha_{2}$ during the process defines the evolution of the thickness and the profile radius curvature in the plane of the table $\left(\mathrm{X}^{\prime}, \mathrm{Z}\right)$ : $\mathrm{R}_{\mathrm{X}}^{\prime}$ and in the vertical plane $\left(\mathrm{Y}^{\prime}, \mathrm{Z}\right)$ : $\mathrm{R}_{\mathrm{Y}}^{\prime}$ (see axes definition on figure 5).

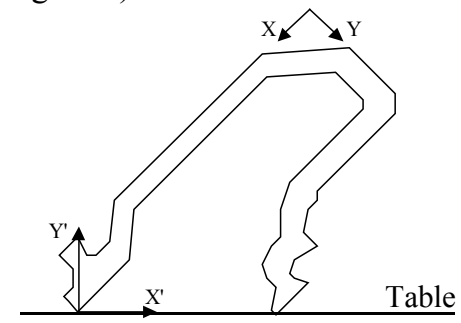

FIGURE 5. Studied profile section: local axes: $X, Y$ and horizontal and vertical axes: $\mathrm{X}^{\prime}, \mathrm{Y}^{\prime}$ 
During the quenching process, the profile is blocked by guides. So, $\alpha_{1}$ and $\alpha_{2}$ are zero, there is no curvature. The temperature becomes inhomogenous. Residual stresses appear. The maximum gap between the hottest and the coldest zones is worth $46^{\circ} \mathrm{C}$ after 1.9 seconds (Figure 6).

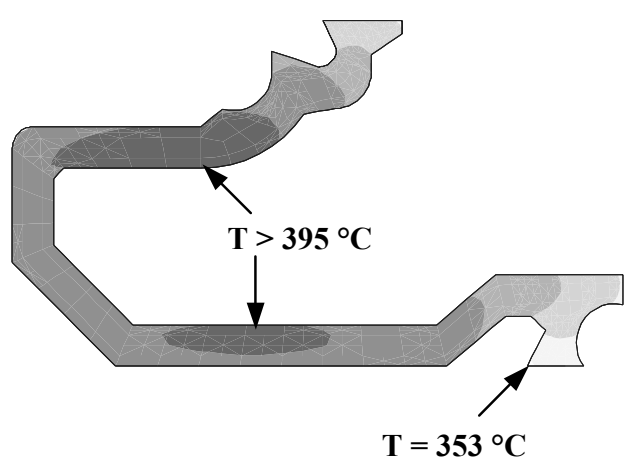

FIGURE 6. Temperature after 1.9 seconds.

Cooling is faster at the ends of the section. So, temperature gradients induce residual stresses.

After this process, the profile leaves the cooling tunnel. Then, a second simulation reproduces the profile state by releasing $\alpha_{1}$ and $\alpha_{2}$ fixations. The profile is then immediately curved due to the effect of residual stresses induced in the tunnel (Figure 7).

The final radius curvatures are calculated $\left(\mathrm{R}_{\mathrm{X}}{ }_{\mathrm{X}}=\right.$ $847 \mathrm{~m}$ and $\mathrm{R}_{\mathrm{Y}}^{\prime}=443 \mathrm{~m}$ ). They consist in comparison points for sensitivity analysis (see Table 4). This will be compared with industrial measurements.

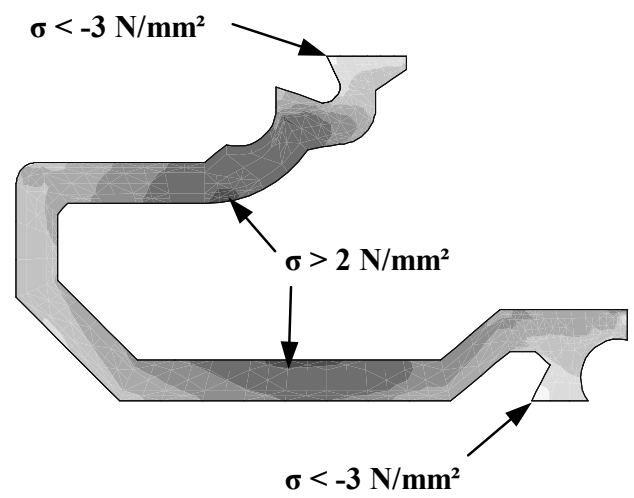

FIGURE 7. Final residual stresses $[-3.54 ; 2.13] \mathrm{N} / \mathrm{mm}^{2}$.

\section{SENSITIVITY ANALYZE}

This analysis has been performed to define the impact of different parameters on final axial curvature.

\section{The initial temperature profile}

Because of the difficulties of the initial temperature measurements, the impact of a difference of $30^{\circ} \mathrm{C}$ has been examined with a homogeneous initial temperature of $470^{\circ} \mathrm{C}$ instead of $500^{\circ} \mathrm{C}$ (case 2). Quite similar results are obtained compared with the previous ones.

\section{Temperature gradients in the section}

Two cases are considered: a gradient of $30^{\circ} \mathrm{C}$ (case 3) and a gradient of $50^{\circ} \mathrm{C}$ (case 4). For theses assumptions, the hottest parts are the thickest ones as observed by infrared measurements.

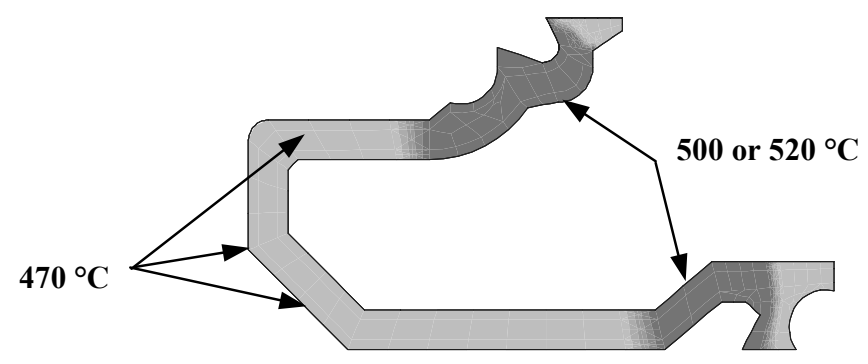

FIGURE 8. Initial temperature.

By examination of the results, we can confirm that this point is essential in final curvature. These new cases modify the shape of the temperature curves in the section and by consequence, the impact on curvature.

\section{The alloy mechanical characteristics}

To evaluate the effect of material characterization on final deformations, the 6082 material characteristics has been replaced by pure aluminum ones (case 5). This point has also an impact on final results.

\section{The water spray temperature}

The speed of cooling was also suspected to be responsible of the final curvature examined here. So, 
the water temperature (case 6) has been modified. After 30 seconds, the section is not completely cooled. Therefore, cooling continued with the ambient air. Final curve was not extremely influenced by this parameter.

\section{DISCUSSION}

TABLE 4. Results of simulations

\begin{tabular}{lcc}
\hline & Rx' $^{\prime}(\mathbf{m})$ & Ry' $^{\prime}(\mathbf{m})$ \\
\hline 1: Reference case & $\mathbf{8 4 7}$ & $\mathbf{4 4 3}$ \\
2: Initial temp. $=\mathbf{4 7 0}^{\circ} \mathbf{C}$ & 916 & 459 \\
3: Temp. grad. $=\mathbf{3 0}^{\circ} \mathbf{C}$ & 546 & 617 \\
4: Temp. grad. $=\mathbf{5 0}^{\circ} \mathbf{C}$ & 349 & 1420 \\
5: Pure aluminum & 534 & 251 \\
6: Water temp. $=\mathbf{8 0}^{\circ} \mathbf{C}$ & 779 & 427 \\
\hline
\end{tabular}

By this table, one notices that the initial distribution of the temperature in the section and the nature of material have a strong effect in the final deformations (cases 3, 4 \& 5). On the other hand, the magnitude of initial temperature and the speed of cooling did not bring significant differences (cases $2 \& 6$ ).

\section{Comparison with industrial curve:}

The curvature in the vertical plan is almost null (thus the radius curvature $\mathrm{R}_{\mathrm{Y}}{ }^{\prime}$ is large) and, in the plan of the table, is in same side as in all of our simulations $\left(\mathrm{R}_{\mathrm{X}}^{\prime}>0\right)$. The amplitude of these deformations approaches the case $n^{\circ} 4$ however one cannot claim that this simulation accurately reproduces the actual phenomena. More complex profile of temperature and other values of heat transfer coefficient could provide identical results. This point shows the interest to improve measurements of the distribution of the temperatures.

\section{CONCLUSION}

For this research, material was studied under different aspects: metallurgical examination, thermophysics and mechanic characterisation. These data are almost untraceable in the literature. So this study provides the required data to simulate the industrial process and to highlight the influence of the various parameters on the quality of the finished product. Such a sensitivity analysis helps the industrial to determine the key parameters responsible of the curvature of their aluminum profiles before straightening step.

\section{ACKNOWLEDGMENTS}

As Research Associate of National Fund for Scientific Research (Belgium), AM Habraken thanks this belgian reasearch fund for its support.

The "Région Wallonne" provides financial support and Hydro Aluminium Raeren actively collaborates to the research. Both are thanked for their help.

\section{REFERENCES}

1. Brandes, E.A., and Brook, G.B., Smithells Metals Reference Book, Seventh edition, pp. 14.14-14.16, 22.1822.21 .

2. Aerospace Structural Metals Handbook, Cindas/Usaf Crda Handbooks Operation, volume 3 (1998), pp. 16.

3. Järvstråt, N., Calculation of thermally induced stress and distortion in extruded aluminium and short fibre composites (1994), pp. 11-33; I:1-I:13, III:1-III:14.

4. Altan, T., Oh, S., Gegel, H., Metal Forming: Fundamentals and Applications, pp. 58.

5. Grober, H., Cescotto, S., Charlier, R., Bourdouxhe, M., Habraken, A.M., Numerical Simulations of Metal Forming Processes, Int. Conf. on Nonlinear Mecanics, Shanghai (1985).

6. Zhu, Y.Y., Cescotto, S., Transient thermal and thermomechanical analysys by F.E.M., Computers and Structures, 1994, 53(2), pp 275-304.

7. Bourdouxhe, M., Charlier, R., Cescotto, S., A finite element for thermomechanical problems. Proc. $2^{\text {nd }}$ Int. Conf. on Numerical Methods in Industrial Forming Processes, Mattiasson, K., Samuelsson, A., Wood, R.D. and Zienkiewicz, O.C. Eds., A.A. Balkema, Rotterdam, Netherlands, 1986, pp 97-102.

8. Schwerdtfeger, K., Gegenwärtiger stand der kenntnis über das Erstarren von Stahl, International Congress of Iron and Steel Industry, Düsseldorf, 1974. 